\title{
Correction to: Determination of transfer stress from ruptured pre-load galvanised tendons in tanks and bund walls
}

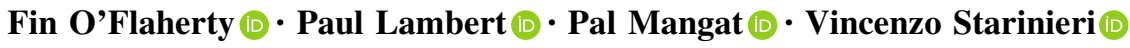

Published online: 4 February 2019

(C) RILEM 2019

Correction to: Materials and Structures (2017) 50:228 https://doi.org/10.1617/s11527-017-1099-2

The article Determination of transfer stress from ruptured pre-load galvanised tendons in tanks and bund walls, written by Fin O'Flaherty, Paul Lambert, Pal Mangat, Vincenzo Starinieri, was originally published online without open access. After publication in volume 50, article ID 228 RILEM decided to grant the author to opt for open choice and to make the article an open-access publication. Therefore, the copyright of the article has been changed to (C) The Author(s) 2018 and the article is forthwith distributed under the terms of the Creative Commons Attribution 4.0 International License (http://creativecommons. org/licenses/by/4.0/), which permits use, duplication, adaptation, distribution and reproduction in any medium or format, as long as you give appropriate credit to the original author(s) and the source, provide a link to the Creative Commons license, and indicate whether changes were made.

The original article can be found online at https://doi.org/10.1617/s11527-017-1099-2.

F. O'Flaherty $(\bowtie) \cdot$ P. Lambert · P. Mangat .

V. Starinieri

Centre for Infrastructure Management, Materials and

Engineering Research Institute, Sheffield Hallam University, Howard Street, Sheffield S1 1WB, UK

e-mail: f.j.oflaherty@shu.ac.uk 